\title{
The Relationship of Root System with the Growth and Development of Bulbs and Shoots in Lilies
}

\author{
Junyang Song ${ }^{1}$ \\ College of Landscape Architecture and Arts, Northwest A\&F University, \\ Yangling 712100, China
}

Additional index words. Liliaceae Lilium, stem roots, basal roots, underground parts, dynamics

\begin{abstract}
Liliaceae Lilium is one of the most famous flower bulbs in the world. The root system bridges substance exchange between the soil and shoot and a strong root system supports the shoot growth and development. During growth, lilies develop two root systems: the basal root system and the stem root system. A few studies have currently reported the relationship between the growth of lily roots and shoots. In our study, we carried out a growth observation of lily shoots (stem and leaves) and underground parts (bulb, basal roots, and stem roots) by cutting the basal roots, stem roots and bulbs of lily. We also discussed how these treatments affected the growth of lilies. The results indicated that both bulb weight and bulb volume showed an initial decreasing and a subsequent increasing trend during growth, and the bulb weight could better reflect bulb nutrient dynamics compared with the bulb volume. The trend in bulb weight was the opposite to that of shoot weight; the bulb weight decreased at first and then increased, whereas the shoot weight first increased and decreased afterward. The turning points for both variations occurred just at the time of flowering. The variation of plant heights showed a typical S-curve and the time where plant heights entered rapid growth coincided with the time where the stem root system started to emerge. The stem root system only took 10 days to complete development. The biological significance was that after plantation, nutrients supporting the growth of the shoots is mainly supplied and maintained by the bulbs and they should be transferred to the stem roots in the shortest delay possible. During early emergence of the stem root system, substance consumed from the bulb are mainly used for the formation of stem roots and after the number of leaves has become stable, substances supplying the shoot growth are mainly from soil nutrients absorbed by the stem roots. The stem root system plays a key role in the growth and development of lily shoots, whereas the basal roots and the bulb would not affect lily growth to a significant level.
\end{abstract}

Lilies (Lilium sp.), a world-famous flowering plant belonging to the Liliaceae Lilium, have a very high ornamental value and occupy an important position in the international flower industry (Suh et al., 2013). The root system serves as a bridge connecting material exchange between the soil and plant shoot. A strong root system is important to ensure the proper growth and development of the shoot. Most studies have focused only on shoots rather than roots due to difficulties in research methods and limited recognition of the root system. Domestic and international studies of the underground parts of lilies mainly focused on the influence of different factors such as planting depth, flurprimidol treatment (Whipker et al., 2011), environmental and climatic factors (Treder, 2008; Xia et al., 2005), and foliar applications of biological agents (De Lucia and Vecchietti, 2012; Zheng et al., 2012) on the growth of bulbs. Recently, the influence of bulb

Received for publication 20 Oct. 2016. Accepted for publication 19 Dec. 2016.

${ }^{1}$ Corresponding author. E-mail: 281168046@ qq.com. sizes on cut flower (Kim and Pak, 2011) and the relationship between bulb refrigeration and dormancy breakage (Niu et al., 2015; Sook, 2012; Suh et al., 2013; Zhang et al., 2011) have undergone extensive studies.

The root system of lily is unique compared with other flower bulbs as it is composed of the basal root system and the stem root system. The fleshy basal roots grow at the basal plate under the bulb, while after the shoot has emerged from the soil and grown to a certain height, the stem roots will grow as fibrous roots between the base of the shoot and the top of the bulb (roots are underneath the soil). Some studies have reported why there are two root systems with different locations and morphologies in lilies, the functions of these roots during lily growth and development and how the root systems are related with the growth and development of lily shoots (Jimmy et al., 1990; Kim et al., 2003). In this study, we observed the shoots (stems and leaves) and underground parts (bulbs, basal roots, and stem roots) of lilies and carried out different treatment (cutting of stem roots, basal roots, and bulbs) to discuss and compare the relationship between shoots and underground parts in terms of lily growth, thereby providing theoretical basis for lily cultivation and management.

\section{Materials and methods}

\section{Materials}

The Oriental $\times$ Trumpet hybrid Yelloween was used as test materials in this study. The perimeter of bulbs ranged between 16 and $18 \mathrm{~cm}$. The experiment was performed in the horticultural field of the Northwest Agriculture and Forestry University. In this study only lily bulbs with a perimeter of $17.70 \pm$ $0.48 \mathrm{~cm}$ were planted. The lilies were planted on 5 Apr. 2009 and harvested on 28 Oct. 2009. The planting environment and managing practices were kept constant.

\section{Methods}

Dynamic growth analysis of lily underground parts and shoots. Bulbs with the same size were selected and their perimeter, weight, and number of basal roots were measured and recorded. During the growth, plants were dug out for dynamic observation and the perimeter of bulbs, number of basal roots, diameter of the distributed stem roots, bulb weight, plant height, number of leaves, and weight of the shoots were measured. Each experiment had 3 repeats and each repeat had 10 plants. Thirty plants were dug out each time and the average values were used for statistical analysis.

The perimeter of bulbs was measured with a soft tape with an accuracy of $0.1 \mathrm{~mm}$ and the weight of bulbs was measured with an electronic scale with an accuracy of $0.01 \mathrm{~g}$. The number of basal roots was measured by counting and the maximum diameter of the distributed stem roots was measured with a caliper with an accuracy of $0.1 \mathrm{~mm}$. The height of the plant was measured from the base to the top with a tape with an accuracy of $1 \mathrm{~mm}$. The number of leaves was measured by counting and the weight of shoots was measured with an electronic scale $(0.01 \mathrm{~g}$ accuracy) after cutting the base of the plant.

The influence of cutting the stem root system on lily growth and development. This experiment consisted of a treatment group and a control group. Each experiment had 3 repeats and each repeat had 10 plants. For the treatment group, the bulbs were planted just underneath the soil surface and once the stem roots emerged, they would immediately be cut. The control group was planted as normal and cultivated without any treatment. The longitudinal and transverse diameters, perimeters and weights of bulbs were measured before planting, and environmental factors and managing practices were kept constant. During the growth, the plant height, leaf length, and width of the shoots were observed. The longitudinal and transverse diameters, perimeters, and weights of bulbs and aboveground parts were measured again during harvesting.

The longitudinal and transverse diameters of bulbs were measured with a caliper with an accuracy of $0.01 \mathrm{~mm}$. Any leaf growing in the middle of the plant was picked for 
measurement and the maximum lengths and widths were measured with a caliper.

The influence of cutting the basal root system on lily growth and development. This was a pot experiment consisting of a treatment group and a control group. Each experiment had 3 repeats and each repeat had 10 plants. The basal roots of the treatment group were completely cut before they were planted. A hole of a diameter of $5 \mathrm{~cm}$ was made at the bottom of the pot and the bulb was planted aligned to the hole. The basal roots were immediately cut once they emerged. The control group was planted in normal pot with basal root system. The environmental factors and managing practices remained constant for both groups. The heights, leaf lengths, and widths of the shoots were monitored. The longitudinal and transverse diameters, perimeter, and weight of bulbs and aboveground parts were measured during harvesting.

The influence of cutting the bulb on lily growth and development. This experiment comprised of a treatment group and a control group. Each experiment had 3 repeats and each repeat had 10 plants. When the stem roots were fully developed, lilies in the treatment group were carefully removed from the cultivation media and cut with the whole bulb (including the basal root system). The stem roots were kept intact and the lilies were replanted into the media. The control group was planted as normal and cultivated without any treatment. The environmental factors and managing practices were kept constant for both groups. The plant heights, leaf lengths and widths, and the weight $\mathrm{s}$ of the shoots were closely observed and measured during harvesting.

Data analysis. Data processing and mapping were conducted on Microsoft Excel 2007 (Microsoft Corp., Redmond, WA). The $\mathrm{T}$ test and correlation analysis were carried out using SPSS17.0.

\section{Results and Analysis}

Dynamic growth analysis of lily underground parts and shoots. Our observation showed that, under proper ambient conditions, lily bulbs would emerge from the soil on the $10 \mathrm{~d}$ after planting, the stem root system would emerge on the $20 \mathrm{~d}$ after planting, squaring would occur on the 40th $\mathrm{d}$ and flowering would be observed on the 90th d, all the time points count start with the day of planting. As shown in Fig. 2, the weight and perimeter of bulbs decreased gradually from planting $(0 \mathrm{~d})$ to flowering (90 d) and increased after flowering. The trough in the changes of weight and perimeter coincided with the time when the aerial part of the plant flowered (90 d). The nadir of bulb weight and perimeter also coincided with the time of plant flowering $(90 \mathrm{~d})$. Statistical analysis suggested that the change of bulb diameter was significantly associated with the weight of bulbs (correlation coefficient is 0.965 ; correlation significant at 0.01 level). The variation of bulb weight was more significant than that of the bulb diameter (Fig. 2). The number of basal roots showed nonsignificant and irregular changes (Fig. 2). The stem roots emerged at $20 \mathrm{~d}$ after planting, with countable 2-3 rounds at first, and then formed a dense root system within $7 \mathrm{~d}$. Figure 2 suggests that within $10 \mathrm{~d}$ after the stem root emerged, the diameter of stem roots grew fastest and then slowed down.

The plant height graph for the growth and development of lilies showed a typical S-curve. As shown in Fig. 1, the plant height grew slowly in the first $10 \mathrm{~d}$ after emergence, with a fast growth period at $20 \mathrm{~d}$ and a slow growth at $60 \mathrm{~d}$ after planting. The number of leaves showed a similar S-variation pattern and the plateau occurred at $40 \mathrm{~d}$ after planting, suggesting that although the number of leaves ceased to grow, the height of plant still increased for another $20 \mathrm{~d}$. In our study, the weight of shoots increased continuously after planting, reached its peak at $90 \mathrm{~d}$ and had

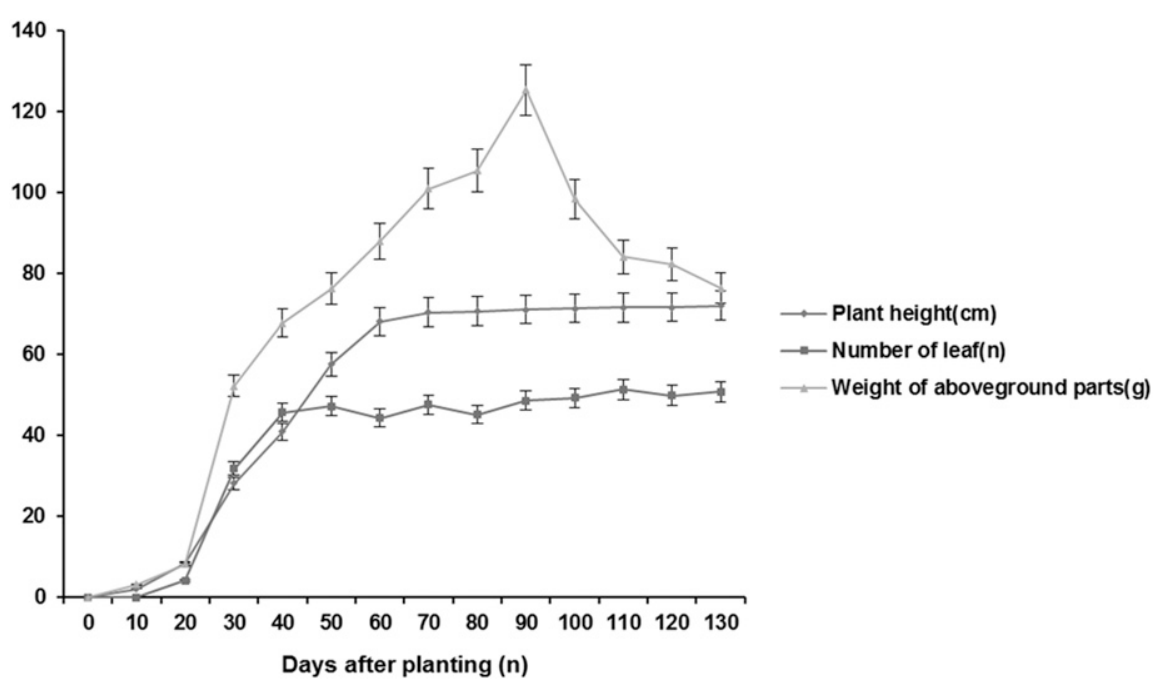

Fig. 1. Dynamic growth of lily aboveground parts.

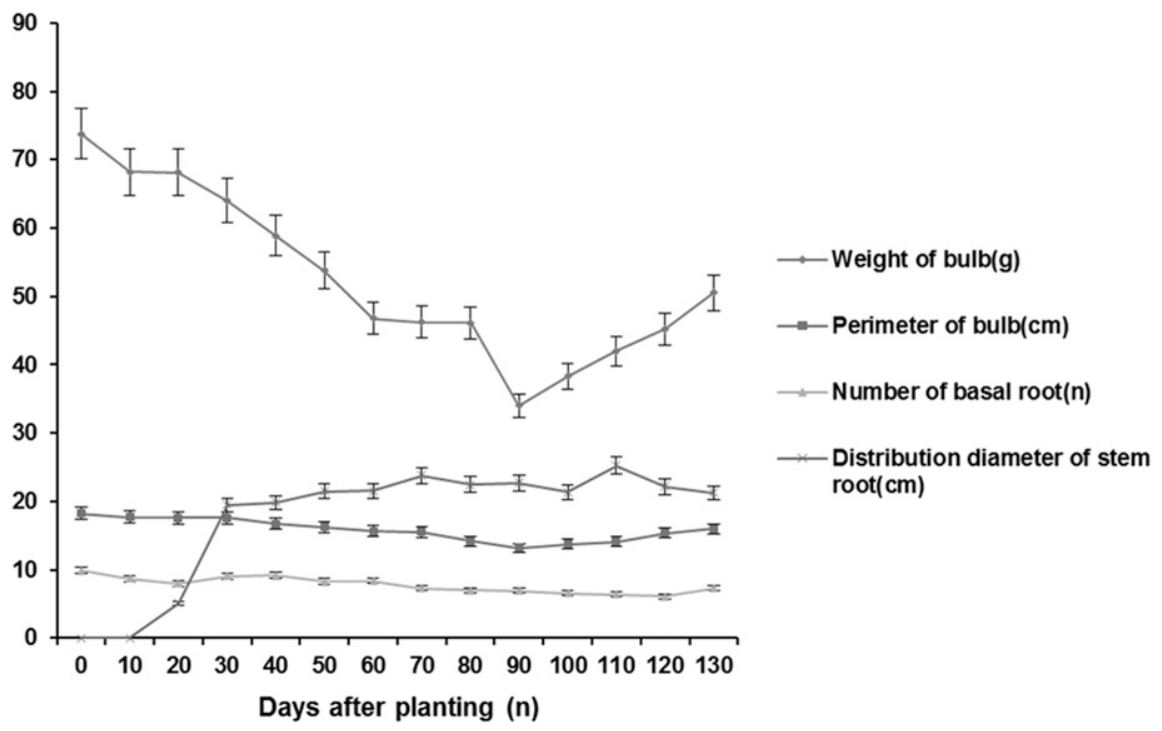

Fig. 2. Dynamic growth of lily underground parts. a gradual decline in the following days, with an obvious peak just occurring at the time point of flowering (90 d after planting) (Fig. 1).

By analyzing the dynamic data of shoots (plant height, number of leaves, and shoot weight) and underground parts (bulb diameter, bulb weight, and stem root diameter) during lily growth, we could see that the variation of bulb weight was opposite to that of shoot weight (Figs. 1 and 2). The weight of bulb had an initial decrease followed by an eventual increase, while the shoot weight increased at first and decreased afterward. The peak of the increase in shoot weight overlapped with the trough of decrease in bulb weight (90 d after planting), with both occurring at the period of flowering. This suggests that for lilies, before flowering, the accumulation of aboveground biomass is partly derived from the bulb. When the plant height remained stable (60 d after planting), it 
meant that the leaves were able to fully undergo photosynthesis. The continuous decrease in the bulb weight in the following days indicated that biomasses accumulated via leaf photosynthesis have not been transferred to the bulb yet and the shoot growth was supported by both the leaf and the bulb. At the flowering period, the photosynthetic biomass accumulated started to flow to the bulb.

The stem root system emerged at $20 \mathrm{~d}$ after planting and completed rapid growth within $30 \mathrm{~d}$ after planting with the stem root remaining at a high level in the following days (Fig. 2). At $40 \mathrm{~d}$ after planting, the number of leaves reached the peak and remained stable. It suggested that the fast formation and development of stem roots were the bases for the rapid growth of the lily shoots (plant height and shoot weight).

The influence of cutting the stem root system on lily growth and development. As shown in Fig. 3, the height of lilies cut with the stem root system was lower than the control during our experiment. The result of data analysis shows there were significant difference between treatment and control (P 0.01). During the early growth period (30 d after planting), the difference was insignificant but as the cultivation progressed the difference became more significant. The variation pattern of plant height in two groups was consistent, suggesting that the stem root system significantly affected the growth of plant height. The nutrients needed for the growth of lily shoots are derived partly from the bulb and partly from the nutrients absorbed by the stem root system in the soil. Our study confirmed that the loss of stem roots significantly influenced the height of lily shoots. As for the variation in leaf lengths and widths, difference occurred at $36 \mathrm{~d}$ after planting and remained at higher level in the following days (Figs. 4 and 5). Results there were significant differences in leaf lengths and widths between treatment and control $(P=0.01)$. These suggested that the loss of stem roots would exert significant negative influence on the growth of lily shoots in terms of the plant height and leaf size.

On the day of plantation (6 Apr.) and harvesting (28 Oct.), bulb longitudinal and transverse diameters, bulb perimeters and weights and shoot weights were measured and the former four indicators were the same in both groups during planting. The measured results of the above indicators on the day of harvesting are shown in Table 1 and Fig. 6. The data showed that after cutting the stem root system all indicators measured in the experiment group were significantly lower than the control and the most prominent difference was detected in the weight of bulb and shoot, with a level decreased respectively by $17.68 \%$ and $49.86 \%$ compared with the control (Table 1; Fig. 6). Statistical analysis suggested that cutting the stem root system significantly affected the perimeters and weights of bulbs as well as the weights of shoots (Table 1), indicating that the stem root system plays a dominant role in the biomass accumulation of lily shoots and bulbs.

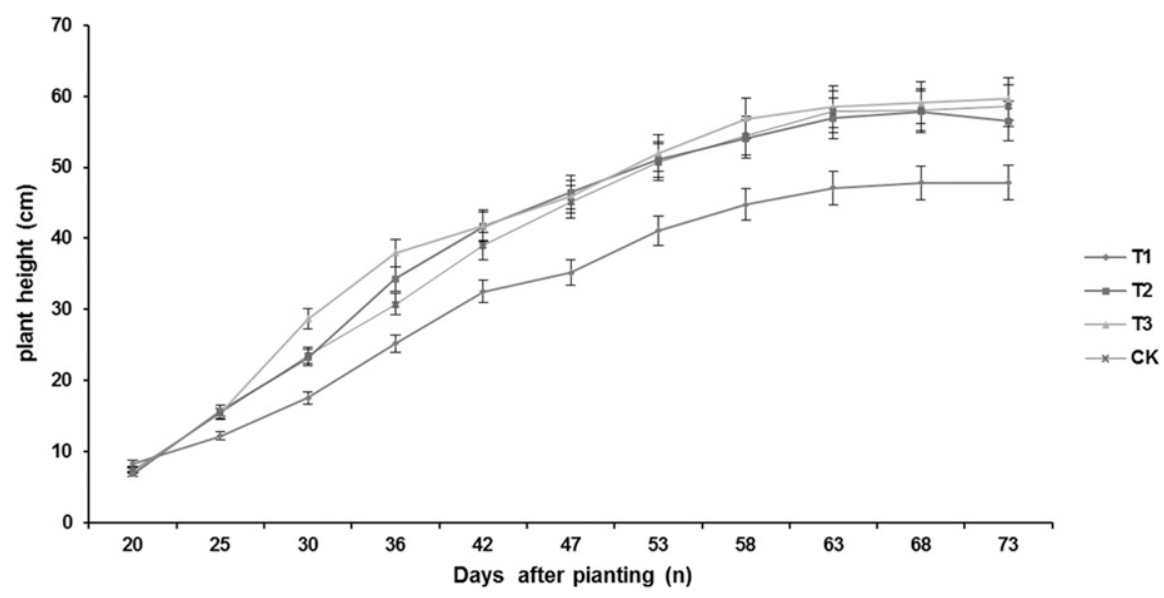

Fig. 3. The influence of different treatment on plant height of lily. T1 = cutting the stem root system; T2= cutting the basal root system; $\mathrm{T} 3$ = cutting the bulb; $\mathrm{CK}=$ control group.

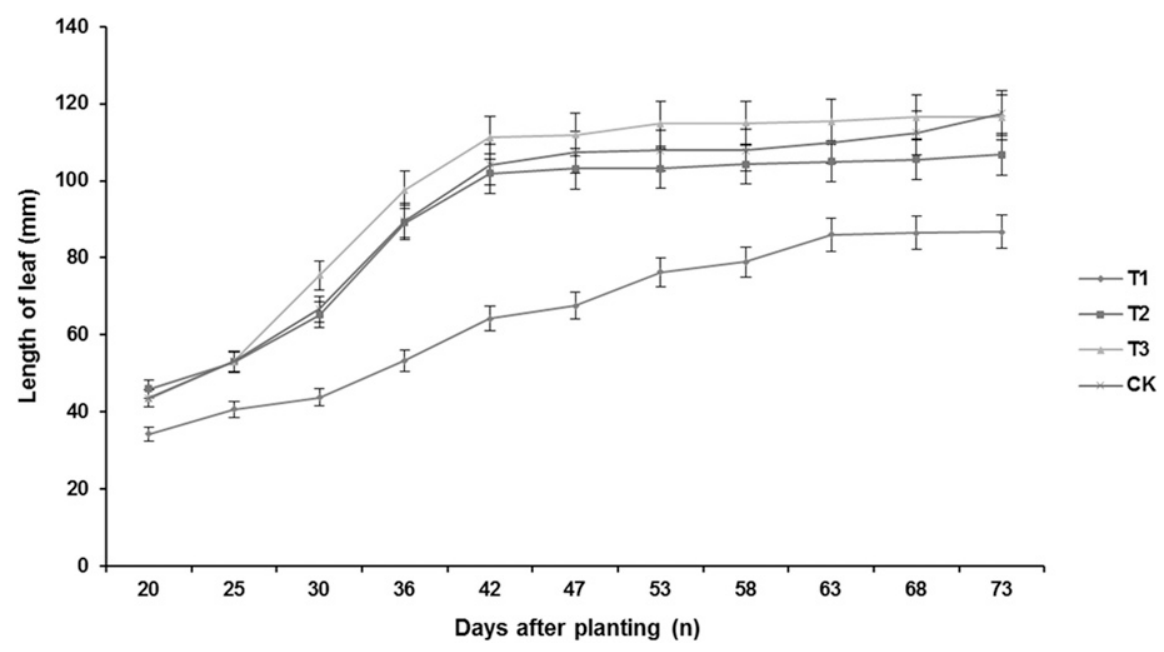

Fig. 4. The influence of different treatment on leaf length of lily. T1 = cutting the stem root system; T2 = cutting the basal root system; $\mathrm{T} 3=$ cutting the bulb; $\mathrm{CK}=$ control group.

The influence of cutting the basal root system on lily growth and development. During the whole observation period, lilies cut with the basal root system did not show a significant difference compared with the control group in terms of their plant heights (Fig. 3) and the leaf lengths (Fig. 4) and leaf widths (Fig. 5) was also insignificantly different from the control in the early growth period (42 d after planting). However, during the days that followed the difference in leaf lengths increased with a small variation. Although the experiment group showed slightly lower levels of aboveground indicators (plant height, leaf length, and width), statistical analysis did not suggest significant difference between the control and experiment group, indicating that the basal root system may not significantly affect the growth and development of lily shoots. Continuous observation of the basal root system showed that during the growth of lilies the number of basal roots did not change significantly (Fig. 2) as the old roots would wither and the new roots would emerge, thus forming an alternative rooting pattern of the old and new roots.

The influence of cutting the basal root system on the weight of lily bulb and shoot is shown in Fig. 7. The bulb volume (longitudinal, transverse diameter, and perimeter) of lilies without the basal root system was slightly lower than the control and the weight of their bulbs and shoots were respectively $11.6 \%$ and $11.53 \%$ lower than the control. Statistical analysis suggested that there is no significant difference between the two groups in terms of bulb longitudinal and transverse diameters, bulb perimeter and weight, and the shoot weight, indicating that cutting of the basal root system insignificantly inhibited the growth of bulb and the accumulation of aboveground biomass and it did not affect the volume of bulb as the longitudinal and transverse diameters and perimeter of bulbs did not change significantly.

The influence of cutting the bulb on lily growth and development. At $25 \mathrm{~d}$ after plantation, the stem root system has almost completed rapid growth and the diameter of stem root distribution remained at a relatively 


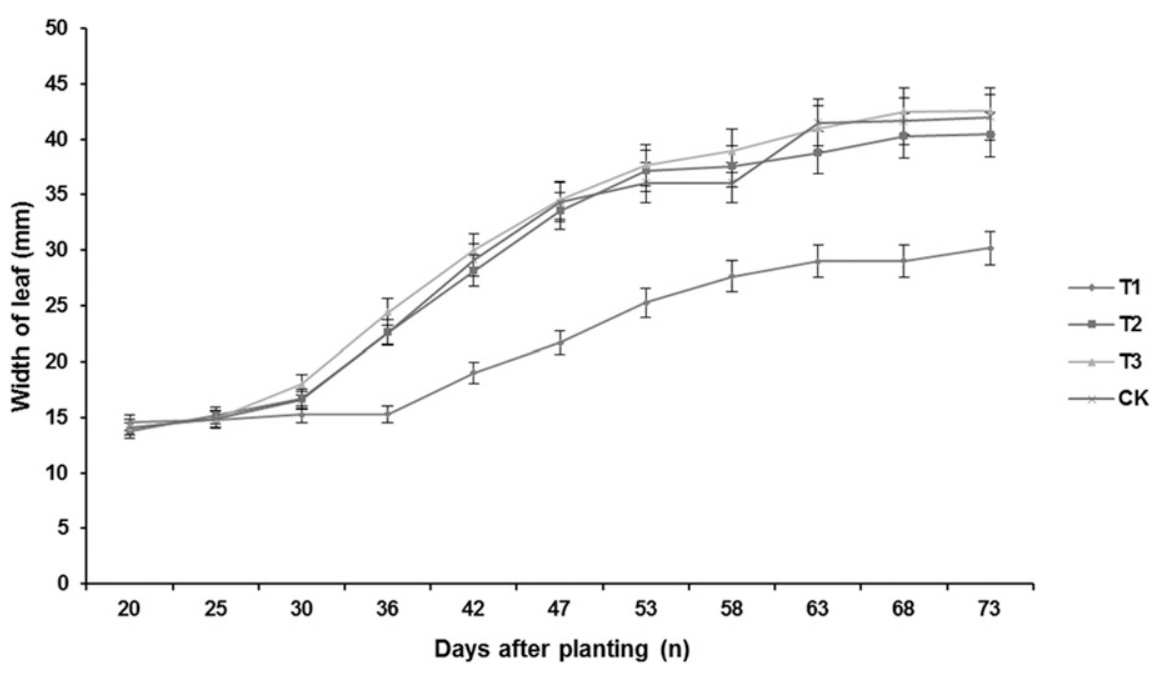

Fig. 5. The influence of different treatment on leaf width of lily. T1 = cutting the stem root system; $\mathrm{T} 2=$ cutting the basal root system; $\mathrm{T} 3=$ cutting the bulb; $\mathrm{CK}=$ control group.

Table 1. The influence of cutting the stem root system on bulb and shoot weight in lily.

\begin{tabular}{lccccc}
\hline Indicator & $\begin{array}{c}\text { Vertical diam } \\
\text { of bulb }(\mathrm{mm})\end{array}$ & $\begin{array}{c}\text { Transect diam } \\
\text { of bulb }(\mathrm{mm})\end{array}$ & $\begin{array}{c}\text { Perimeter of } \\
\text { bulb }(\mathrm{cm})\end{array}$ & Wt of bulb $(\mathrm{g})$ & $\begin{array}{c}\text { Wt of } \\
\text { aerial part }(\mathrm{g})\end{array}$ \\
\hline Treatment & $43.44 \pm 5.85^{* *}$ & $49.77 \pm 5.70^{* *}$ & $15.98 \pm 2.38^{* *}$ & $72.06 \pm 24.69^{* *}$ & $35.39 \pm 9.67^{* *}$ \\
Control & $47.24 \pm 3.79$ & $58.53 \pm 4.61$ & $19.32 \pm 1.20$ & $87.54 \pm 18.45$ & $70.58 \pm 14.79$ \\
\hline
\end{tabular}

T test was used for analysis.

*Means difference significant $(P<0.05)$.

$* *$ Means difference extremely significant $(P<0.01)$.

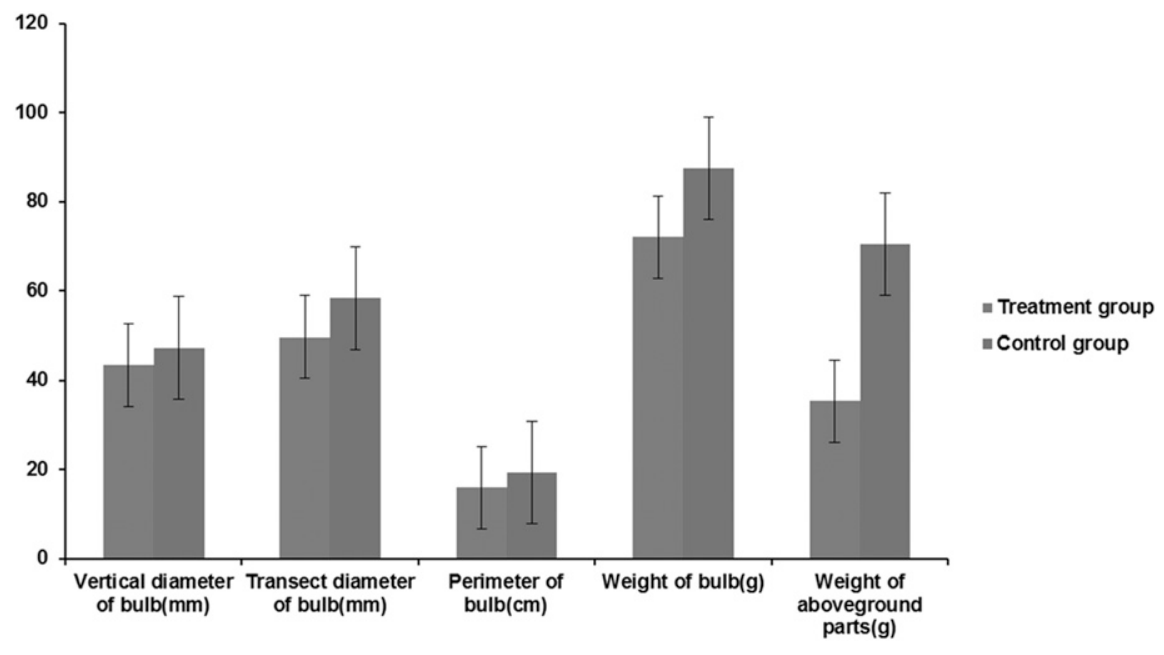

Fig. 6. The influence of cutting the stem root system on lily.

high level. At this time point, the whole bulb was cut and experiment results are shown on Figs. 3-5. Lilies cut with bulbs (at $25 \mathrm{~d}$ after planting) only showed insignificant difference in plant height and leaf width and length comparing to the control. During the observation period, the leaf length in the experiment group was slightly higher but the leaf width and plant height was sometimes higher in the experiment group and sometimes higher in the control group. On 28 Oct., lilies were harvested and the shoot weight in the experiment group was $64.57 \mathrm{~g}$, which was $8.52 \%$ lower than that of the control $(70.58$ g). Statistical analysis suggested no significant difference between two groups. When the two indicators are associated with each other. According to our study of lily bulb growth, the variation of bulb volume and weight both showed an initial decreasing followed by an increase and the turning point occurred at the period of flowering. The magnitude of bulb weight variation was much more significant than that of the bulb volume (Fig. 2), which indicates that the variation of bulb weight could better reflect the accumulation and consumption of nutrients in the lily bulb. Such variation pattern implies that, using the start of flowering as a landmark, the lily bulb underwent a consuming process before flowering and the substances or energy were used for shoot growth; after flowering, the lily bulb started to accumulate biomass, thereby saving nutrients for winter and the next-year growth. Zhang et al. (1995) carried out a dynamic observation of Lilium dauricum bulb diameter and reported a variation pattern similar to our study. In their study, the change of bulb volume fluctuated widely and the bulb diameter during the late growth period even exceeded that on plantation, we believe the reliability of this study is low. It is improper to use bulb diameter to reflect the consumption and accumulation of nutrient substances in the bulb. Zhou et al. (2003) observed the dynamical growth of Lilium longiflorum bulb, and found that the weight of bulb increased slowly in the early growth period and soared during the early flowering period. Many studies suggest that the bulb weight would decrease in the early growth period and this was confirmed in our study. We also found that the bulb weight increased during lily flowering. Liu and Wei (1994) observed the growth of Lilium davidii bulb and also reported that the variation of bulb weight showed decreasing followed by a subsequent increasing trend but the increase of weight occurred in squaring period, which is inconsistent with our result. This may because they used bulb that weighed $22 \mathrm{~g}$ as the experiment material.

Within $20 \mathrm{~d}$ after the first emerging of stem roots, the diameter of stem root distribution completed rapid growth (Fig. 2), indicating that the root structure and function have been developed within such a short time. The biological significance is that after lilies have emerged from the soil, the supply and maintenance of nutrients for shoot growth should be substituted from the bulb to the stem root system as the bulb contains limited nutrients and also requires assimilates from the shoots to guarantee the increase of bulb weight for overwintering. This study suggests that in the early growth period ( $20 \mathrm{~d}$ after planting), the bulb nutrients are partly supplied to the growth of leaves and partly to the formation of stem roots. When the number of leaves remained unchanged ( $40 \mathrm{~d}$ after planting), substances and energy stored within the bulb were mainly used for the development of stem roots rather than the shoots. After that the substances supplying for the rapid shoot growth would be soil nutrients absorbed by the stem root system. 


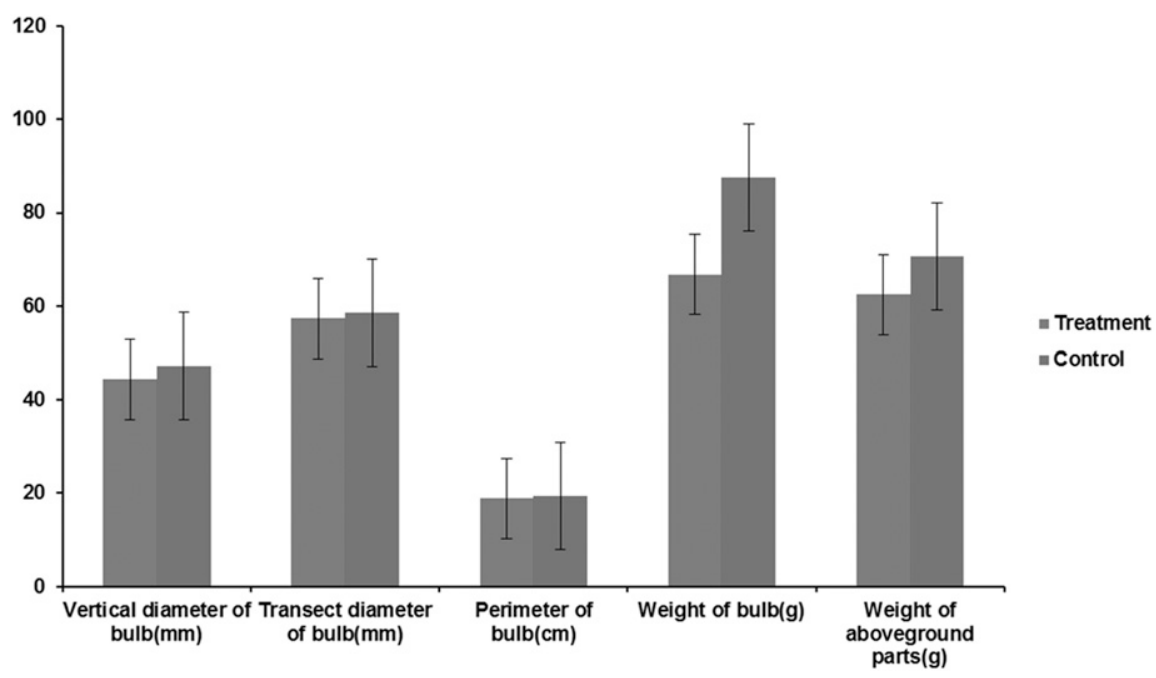

Fig. 7. The influence of cutting the basal root system on bulb and shoot weight in lily.

This suggestion is based on the observation that rapid growth of the shoots (plant height and shoot weight) occurred at $20 \mathrm{~d}$ after plantation, and the time of stem root formation was also $20 \mathrm{~d}$ after plantation. At $30 \mathrm{~d}$ after planting, the stem root system was fully developed and the number of leaves stopped to increase at $40 \mathrm{~d}$ after planting. At this time point, the plant height was only around $40 \mathrm{~cm}$ but the increasing rate of plant height and shoot weight reached to its peak at about 30 $60 \mathrm{~d}$ after plantation (Figs. 1-2). Loss of stem roots significantly inhibited the growth of lily shoots (Table 1), and cutting the basal root system or the whole bulb did not show significant influence on the growth and development of lily shoots (Figs. 3-5).

The technique of casing basin culture was adopted in cultivation of chrysanthemum (sleeve a pot on the chrysanthemum young plant about $30 \mathrm{~cm}$ height from bottom, added soil, which will helpful to the formation of the stem root, after budding the roots in soil was cut off), which can enhance the quality of chrysanthemum (Chen et al., 2015) and indicated that the stem root was important to chrysanthemum over ground part growth and development. The stem root of maize was very important to the quantity (Zhang et al., 2014). Song et al., found that soil ridging treatment can stimulate the formation of the stem root in maize and enhance the root absorbing ability of water and nutrient (Song et al., 2008).We can therefore conclude that the stem root system is critical for the growth and development of lily shoots.

Many scholars (Zhang et al., 1995) believe that the basal root system can cause downward migration of the stem root system and the number of basal roots would remain stable during the growth of lilies (Fig. 2). After cutting the basal root system or removing the whole bulb after the stem root system has fully developed, the aboveground shoots could still grow normally and they showed no significantly different indicators when compared with the control. We therefore believe that in the late growing period the basal root system and the bulb would not significantly affect the growth and development of lily shoots. In the experiment of bulb cutting, we accidentally found that many bulblets emerged at the site of stem roots indicating that in the late growing period the transporting nutrients from shoots to roots is a survival instinct for lily. This mechanism helps in the accumulation of nutrients in bulbs to allow plants withstand the winter. Under bulb-cut conditions, nutrients transported to the root could not be stored within the mother bulb and thus a lot of bulblets emerged around the stem roots.

The limitation of this study is that we did not cover the whole period of lily growth and development. Our study of shoot and underground part growth only lasted for $130 \mathrm{~d}$ after plantation and the cutting experiment only lasted for $73 \mathrm{~d}$ after plantation (flower withered). On the day of harvesting (28 Oct., $205 \mathrm{~d}$ after plantation), the shoots were still in the fresh state, thus the changing process of lily shoots and underground parts after our observation is unknown. Further study should involve a process where the shoots undergo withering and the nutrients flow toward the underground parts and a process where the underground parts undergo withering and dying.

\section{Conclusion}

1. During the growth and development of lilies, both the weight and volume of bulb showed an initial decreasing and a subsequent increasing trend. The variation of bulb weight was more significant than the bulb volume. The bulb weight could better reflect the dynamics of bulb nutrients than the bulb volume.

2. During the dynamic growth and development of lilies, the change of bulb weight was opposite to that of the shoot weight. The bulb weight showed an initial decreasing and a subsequent increasing trend, while the shoot weight showed a first increasing and a subsequent decreasing variation. The trough and peak for two indicators both occurred just at the time point of flowering.

3. The variation of lily plant height showed a typical S-curve. The same time point where the plant height entered rapid growth corresponded with the time point where the stem root system started to emerge.

4. Within $10 \mathrm{~d}$ after the first emerging of stem roots, the diameter of stem root distribution has completed rapid growth. The biological significance of this is that, after planting, the supply and maintenance of nutrients for germination and shoot growth should be substituted from the bulb to the stem root system as soon as possible.

5. The stem root system plays a key role to the growth and development of lily shoots, while the basal roots and the bulb would not affect lily growth to a significant level.

\section{Literature Cited}

Chen, Z., J. Wang, J. Sun, and M. Wang. 2015. Study on high efficient cultivation technique in Chrysanthemum. Chinese Horticulture Abstracts $28-29$

De Lucia, B. and L. Vecchietti. 2012. Type of biostimulant and application method effects on stem quality and root system growth in L.A. Lily. Eur. J. Hort. Sci. 77:10-15.

Jimmy, L.T., J.B. David, and W.W. John. 1990. Effect of stem root on growth and flowering of Asiatic lilies. HortScience 25:625.

Kim, H.J., J.M. Kim, D.C. Choi, J.S. Choi, and Y.G. Choi. 2003. Bulb scale removal on vegetative growth, flowering, and flower quality of Lilium spp. Hort. Environ. Biotechnol. 44:829-832.

Kim, J. and C.H. Pak. 2011. Effects of bulb circumference and cultivar on the cut flower quality in lily. Flower Res. J. 19:197-201.

Liu, J.C. and Z.X. Wei. 1994. Disciplinary study on the increase of fresh weight in Lilium davidii var willmottiae. China Vegetables 27-30.

Niu, L.J., B. Li, W.B. Liao, Y.C. Zhu, M. Wang, X Jin, and Q.Q. Xu. 2015. Effect of nitric oxide on dormancy release in bulbs of oriental lily (Lilium orientalis) 'Siberia'. J. Hort. Sci. Biotechnol. 90:594-598.

Song, R., C. Wu, and Y. Yue. 2008. Effect of soil ridging on the characteristics of corn nodal root. J. Northeast Normal Univ. (Natural Sciences Edition) 40:132-135.

Sook, P.I. 2012. Changes in morphological characteristics and sugar contents according to harvest time and cold storage duration in Lilium oriental hybrids bulbs. Flower Res. J. 20:204-210.

Suh, J.K., X.W. Wu, A.K. Lee, and M.S. Roh. 2013. Growth and flowering physiology, and developing new technologies to increase the flower numbers in the Genus Lilium. Hort. Environ. Biotechnol. 54:373-387.

Treder, J. 2008. The effects of cocopeat and fertilization on the growth and flowering of oriental lily 'Star'. J. Fruit Ornam. Plant Res. 16:361-370.

Whipker, B.E., I. McCall, J. Barnes, W. Buhler, B. Krug, C. Currey, and R. Lopez. 2011. Flurprimidol preplant bulb soaks control growth of 
potted Liliums, p. 79-87. In: A. Grassotti and G. Burchi (eds.). 2nd International Symposium on the Genus Lilium, Acta Horticulturae Vol. 900, Pescia, Italy.

Xia, Y.P., H.J. Zheng, and C.H. Huang. 2005. Studies on the bulb development and its physiological mechanisms in Lilium oriental hybrids, p. 91-98. In: H. Okubo, W.B. Miller, and G.A. Chastagner (eds.). 9th International Symposium on Flower Bulbs, Acta Horticulturae, Niigata, Japan.
Zhang, X.F., H.B. Yu, and H.W. Liu. 1995. Reproductive biology of Lilium dauricum (VI)dynamics of the underground part. J. Northeast Forestry Univ. 23:22-27.

Zhang, Y.J., Z.K. Xie, Y.J. Wang, and L.P. An. 2011. Changes in carbohydrate metabolism and bulb growth as induced by low-temperature release of dormancy in lily bulbs. Philipp. Agr. Sci. 94:149-154.

Zhang, Y., H. Qin, L. Wu, J. Zhang, Z. Li, M. Huang, and L. Jiang. 2014. Growth characteristics and the effect of nitrogen application on the maize root. Zhongguo Nongye Daxue Xuebao 19:62-70.

Zheng, R.R., Y. Wu, and Y.P. Xia. 2012. Chlorocholine chloride and paclobutrazol treatments promote carbohydrate accumulation in bulbs of Lilium Oriental hybrids 'Sorbonne'. J. Zhejiang Univ. Sci. B 13:136-144.

Zou, H.G., Y.F. Ning, and R.L. Jiang. 2003. Dynamic changes of development of characters in Lilium longiflorum. Northern Hort. 60-61. 